\title{
Behavior of Trip Length Distribution Pattern due to the Variation of Trip Length Interval Determination
}

\author{
Hitapriya Suprayitno ${ }^{1}$, Vita Ratnasari ${ }^{2}$, Nina Saraswati ${ }^{1}$
}

\begin{abstract}
Transport Model is always needed and important for developing Transportation System Master Plan. Trip Distribution is one of the important parts of Transport Model, which is a result mathematical operation of trip generation and deterrence function. Trip Length Distribution Pattern is the foundation of Deterrence Function. The trip length distribution pattern can change due to the various trip length interval used. Analog to this, the Deterrence Function can also change. The research result indicate that the distribution pattern change significantly on trip length interval $1 \mathrm{ko}$ km. For trip length interval of 4 to $8 \mathrm{~km}$, the trip length distribution indicate the general characteristic of trip length distribution, i.e. the number of trips is high in short distance and getting down in the longer trip distance. The trip interval of $7 \mathrm{~km}$ gives the most accepted Tanner Deterrence Function.
\end{abstract}

Keywords_ - Trip Length Distribution, Trip Length Distribution Behavior, Trip Length Interval Variation.

\section{INTRODUCTION}

A master plan of transportation system, either urban, regency, provincial or national need to be reviewed and re-developed for each 5 year. This kind of work needs a transportation model. Among the four model of the four step transportation modeling, the Trip Distribution (TD) Model is the one which is used to predict future transportation demand. TD Model itself is a result of a mathematical operation between the product of Trip Generation Model with a Deterrence Function [1]-[6].

Deterrence Function is a mathematical model of the Trip Length Distribution (TLD). The TLD Pattern seems change due to various Trip Length Interval used. Hence, the Deterrence Function changes also accordingly. This change influences strongly the result of Trip Distribution Model in term of Origin Destination Matrix [1]. Therefore, it is very important to understand the behavior of TLD Pattern due to the variation of Trip Length Interval used. Caution must be taken in determining the Trip Length Interval to develop TLD Pattern.

TLD Pattern should follow general characteristics of TLD: the number of trips is high in short distances and gradually lesser and lesser as the trip distance getting higher and higher. Sometimes, the number of trip can be significantly small in very short distance, follow by a peak value and gradually less and less [1], [7]-[9]. These general characteristics, in European custom transport modeling, normally are modeled by three mathematical formulas: negative power model, negative exponential model and Tanner model.

\footnotetext{
${ }^{1}$ Hitapriya Suprayitno and Nina Saraswati are with Department of Civil Engineering, Institut Teknologi Sepuluh Nopember (ITS), Surabaya, 60111, Indonesia. E-mail: suprayitno.hita@gmail.com.

${ }^{2}$ Vita Ratnasari is with ${ }^{\text {Department }}$ of Statistics, Institut Teknologi Sepuluh Nopember (ITS), Surabaya, 60111, Indonesia.
}

Tanner model is in fact a multiplication of negative power model and negative exponential model [1]. While in the United States the deterrence function, which is called as friction factor, quite often modeled by five probability density functions: Poisson, Chi Square, Log Pearson Type III, Gamma and Weibull [9].

Gravity Model with Deterrence Function developed based on Trip Length Distribution Pattern with Trip Length Interval $=1$ still can be found [10]. This generates a big question: Is using TLD Pattern with Trip Length Interval = 1 is appropriate enough?

This paper presents a small research to investigate this behavior. The principal question is how the distribution pattern change due to the trip length interval used and which trip length interval should be used to develop a Deterrence Function. A population of 50 staffs of BRI Bank Diponegoro Branch Office was taken for the research. The distances between the office to their houses were taken as working trip length with a certain distribution pattern.

\section{II.METHOD}

The research was conducted by following these steps: stating the background of the research, defining the research objective, doing related literature review, developing the experiment design, conducting the experiment and ended by drawing conclusions.

\section{LITERATUR REVIEW}

\section{A. Trip Distribution}

Among various Synthetic Trip Distribution Model, the Gravity Model is the most popular and the most widely used. The Gravity Model is formulated generally by the following Equation [1].

$$
\mathrm{T}_{\mathrm{ij}}=\mathrm{P}_{\mathrm{i}} \mathrm{A}_{\mathrm{j}} \mathrm{f}\left(\mathrm{C}_{\mathrm{ij}}\right)
$$


In general, the Gravity Model knows three types of Deterrence function - $\mathrm{f}\left(\mathrm{C}_{\mathrm{ij}}\right)$. Those three Deterrence Function are presented below [1].
- Negative Power
$: \mathrm{f}(\mathrm{C}) \quad=\mathrm{C}^{-\alpha}$
- Negative Exponential : $\mathrm{f}(\mathrm{C}) \quad=\mathrm{e}^{-\beta \mathrm{C}}$
- Tanner$$
\mathrm{f}(\mathrm{C}) \quad=\mathrm{C}^{-\alpha} \times \mathrm{e}^{-\beta \mathrm{C}}
$$

\section{B. $\quad$ Non Linear Model Curve Fitting}

Non Linear Model is developed based on least square principle, by minimizing the Sum of Square Error (SSE). A non-linear model could be developed by using a trial-anderror iterative process. The Non-Linear Model quality is measured by using goodness of fit and maximum acceptable error parameters, as presented below [5], [6], [11]-[13].

Goodness of Fit :

$\mathrm{H}_{0} \chi^{2} \leq \chi_{0}^{2}$; curve pattern is considered the same as the reference

$\mathrm{H}_{1} \chi^{2} \leq \chi_{0}^{2}$; curve pattern is considered not the same as the reference

$$
\begin{array}{ll}
\chi^{2} & =\Sigma\left(\mathrm{y}_{\mathrm{i}}-\mathrm{y}_{\mathrm{i}}^{0}\right)^{2} / \mathrm{y}_{\mathrm{i}}^{0} \\
\chi^{2}{ }_{0} & =\chi^{2}(\mathrm{v}, \alpha / 2) \\
\mathrm{u} & =\mathrm{n}-\mathrm{k}-1
\end{array}
$$

where:

$\chi^{2}{ }_{0}$ : the reference $\chi^{2}$ value, at a certain $v$ and $\alpha$ value

$\chi^{2}$ : the regression line $\chi^{2}$ value

$\mathrm{y}^{\mathrm{m}_{\mathrm{i}}}$ : the $\mathrm{y}_{\mathrm{i}}$ value of the model

$\mathrm{y}_{\mathrm{i}}^{0}$ : the $\mathrm{y}_{\mathrm{i}}$ value of the TLD

$\mathrm{n}$ : number of trip length distribution points

$\mathrm{k}$ : number of observed parameters

Maximum Acceptable Error:

$$
\begin{array}{ll}
\mathrm{H}_{0} & |\overline{\mathrm{e}}| \leq \mathrm{E} \text {; the case is accepted } \\
\mathrm{H}_{1} & |\overline{\mathrm{e}}|>\mathrm{E} ; \text { the case is rejected } \\
|\overline{\mathrm{e}}| & =\Sigma\left|\mathrm{e}_{\mathrm{i}}\right| / \mathrm{n} \\
\left|\mathrm{e}_{\mathrm{i}}\right| & =100 \mathrm{x}\left|\mathrm{y}^{\mathrm{m}}{ }_{\mathrm{i}}-\mathrm{y}^{0}{ }_{\mathrm{i}}\right| / \mathrm{y}_{\mathrm{i}}^{0}
\end{array}
$$

where:

E : the Maximum Acceptable Error, in percentage

$|\overline{\mathrm{e}}| \quad$ : the absolute average error value

$\mathrm{e}_{\mathrm{i}} \quad$ : the $\mathrm{i}^{\text {th }}$ error

$\mathrm{n} \quad$ : number of trip length distribution points

$\mathrm{y}^{\mathrm{m}_{\mathrm{i}}} \quad$ : the yi value of the model

$\mathrm{y}^{0}{ }_{\mathrm{i}} \quad$ : the yi value of the TLD

\section{ANALYSIS OF TRIP LENGTH DisTRIBUTION}

\section{A. Research Objective and Experiment Design}

The Research Objective is to understand the Behavior of Trip Length Distribution Pattern due to the Variation of Trip Length Interval used. In other words, the research tries to learn how the TLD Pattern changes due to the Trip Length Variation Interval. Experiment was designed by taking data on employee working trip, means the distance between the employee houses to the office.

\section{B. Experiment Case}

The working trip of the BRI Branch Office Diponegoro Employee, in Surabaya was taken as the case. The distances between the employee houses to the office are presented in table Attachment 1.

\section{Trip Length Distribution Pattern Behavior}

A Trip Length Data, consists of 50 trip length data, can produce various Trip Length Distribution Pattern and its Deterrence Function due to the Trip Length Interval used. This behavior is analyzed below. Tanner Deterrence Function is developed based on Trip Length. The formula is presented below.

$$
f(L)=C x L^{-\alpha} \times e^{-\beta L}
$$

where:

$$
\begin{array}{lll}
\mathrm{f}(\mathrm{L}) & : & \text { deterrence function } \\
\mathrm{C} & : & \text { constant } \\
\mathrm{L} & : & \text { trip length } \\
\alpha, \beta & : & \text { deterrence function coefficient }
\end{array}
$$

\section{Trip Length Interval $1 \mathrm{~km}$}

Calculation result for Trip Length Interval $=1$ indicate that the TLD Pattern is very irregular and is not in concordance to the general rule of TLD Pattern. The Tanner Model has been developed and the result indicates that the Curve Fitting is Not Accepted and the Error is also Not Accepted. The Trip Length Interval $=1$ is not appropriate to be used for developing Deterrence Function.

The Deterrence Function, the graph of TLD Pattern with Deterrence Function and also the Calculation is presented in Equation 11, Figure 1 and Table 1 below.

$$
\begin{aligned}
& \mathrm{f}(\mathrm{L})=3.8 \times \mathrm{L}^{-0.01} 2 \mathrm{x} \mathrm{e}^{-0.04 \mathrm{~L}} \\
& \chi^{2}=\mathrm{DIV} / 0 !>30.14 \quad \rightarrow \text { Not Accepted } \\
& \text { Error }=\mathrm{DIV} / 0 !>10 \% \quad \rightarrow \text { Not Accepted }
\end{aligned}
$$

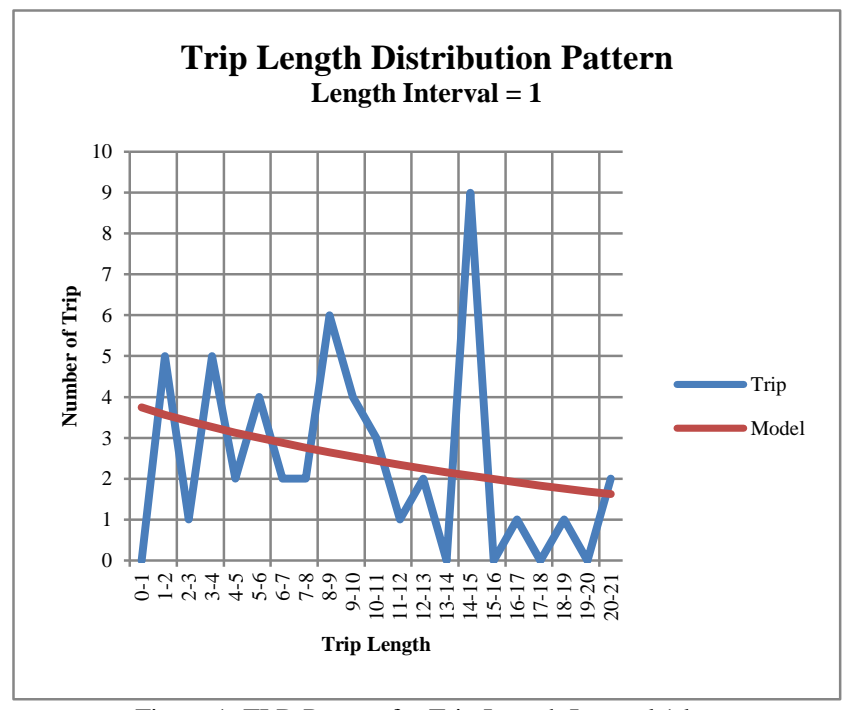

Figure 1. TLD Pattern for Trip Length Interval $1 \mathrm{~km}$ 
TABLE 1.

TANNER DETERRENCE FUNCTION DEVELOPMENT FOR TRIP LENGTH INTERVAL $1 \mathrm{KM}$

\begin{tabular}{|c|c|c|c|c|c|c|c|c|}
\hline \multicolumn{9}{|c|}{ INTERVAL $1 \mathrm{KM}$} \\
\hline \multicolumn{2}{|c|}{ Data } & \multicolumn{5}{|c|}{ Model Development } & \multicolumn{2}{|c|}{ Acceptance } \\
\hline \multirow{2}{*}{ Range } & \multirow{2}{*}{ Trip } & $\mathbf{C}$ & $\mathbf{a}$ & b & \multirow{2}{*}{ Model } & \multirow{2}{*}{$\mathbf{e}_{i}^{2}$} & Curve & Error \\
\hline & & 3.8 & 0.01 & 0.04 & & & $<30.14$ & $<10 \%$ \\
\hline $0-1$ & 0 & 3.8 & 1.007 & 0.980 & \#DIV/0! & 14.067 & \#DIV/0! & \#DIV/0! \\
\hline $1-2$ & 5 & 3.8 & 0.996 & 0.942 & 3.564 & 2.061 & 0.41 & 28.72 \\
\hline $2-3$ & 1 & 3.8 & 0.991 & 0.905 & 3.407 & 5.794 & 5.79 & 240.70 \\
\hline $3-4$ & 5 & 3.8 & 0.988 & 0.869 & 3.262 & 3.019 & 0.60 & 34.75 \\
\hline $4-5$ & 2 & 3.8 & 0.985 & 0.835 & 3.127 & 1.269 & 0.63 & 56.33 \\
\hline $5-6$ & 4 & 3.8 & 0.983 & 0.803 & 2.998 & 1.004 & 0.25 & 25.05 \\
\hline $6-7$ & 2 & 3.8 & 0.981 & 0.771 & 2.876 & 0.767 & 0.38 & 43.78 \\
\hline $7-8$ & 2 & 3.8 & 0.980 & 0.741 & 2.759 & 0.576 & 0.29 & 37.95 \\
\hline $8-9$ & 6 & 3.8 & 0.979 & 0.712 & 2.647 & 11.240 & 1.87 & 55.88 \\
\hline $9-10$ & 4 & 3.8 & 0.978 & 0.684 & 2.541 & 2.129 & 0.53 & 36.48 \\
\hline $10-11$ & 3 & 3.8 & 0.977 & 0.657 & 2.439 & 0.315 & 0.10 & 18.71 \\
\hline $11-12$ & 1 & 3.8 & 0.976 & 0.631 & 2.341 & 1.798 & 1.80 & 134.10 \\
\hline $12-13$ & 2 & 3.8 & 0.975 & 0.607 & 2.247 & 0.061 & 0.03 & 12.37 \\
\hline $13-14$ & 0 & 3.8 & 0.974 & 0.583 & 2.158 & 4.655 & \#DIV/0! & \#DIV/0! \\
\hline $14-15$ & 9 & 3.8 & 0.974 & 0.560 & 2.071 & 48.004 & 5.33 & 76.98 \\
\hline $15-16$ & 0 & 3.8 & 0.973 & 0.538 & 1.989 & 3.956 & \#DIV/0! & \#DIV/0! \\
\hline $16-17$ & 1 & 3.8 & 0.972 & 0.517 & 1.910 & 0.828 & 0.83 & 90.97 \\
\hline $17-18$ & 0 & 3.8 & 0.972 & 0.497 & 1.834 & 3.363 & \#DIV/0! & \#DIV/0! \\
\hline $18-19$ & 1 & 3.8 & 0.971 & 0.477 & 1.761 & 0.579 & 0.58 & 76.09 \\
\hline $19-20$ & 0 & 3.8 & 0.971 & 0.458 & 1.691 & 2.859 & \#DIV/0! & \#DIV/0! \\
\hline $20-21$ & 2 & 3.8 & 0.970 & 0.440 & 1.624 & 0.141 & 0.07 & 18.81 \\
\hline & & & & & & 108.487 & \#DIV/0! & \#DIV/0! \\
\hline & & & & \multicolumn{3}{|c|}{ Acceptance } & NA & NA \\
\hline
\end{tabular}

\section{Trip Length Interval $2 \mathrm{~km}$}

Calculation result for Trip Length Interval $=2$ indicate that the TLD Pattern is very irregular and is not in concordance to the general rule of TLD Pattern. The Tanner Model has been developed and the result indicates that the Curve Fitting is Not Accepted and the Error is also Not Accepted. The Trip Length Interval $=2$ is not appropriate to be used for developing Deterrence Function.

The Deterrence Function, the graph of TLP Pattern with Deterrence Function and also the Calculation is presented in Equation 12, Figure 2 and Table 2 below.

$$
\begin{array}{lll}
\mathrm{f}(\mathrm{L})=9.0 \times \mathrm{L}^{-0.01} \times \mathrm{e} \mathrm{e}^{-0.06 \mathrm{~L}} & \\
\chi^{2}=19.37>16.92 & \rightarrow \text { Not Accepted } \\
\text { Error }=71.84 \%>10 \% & \rightarrow \text { Not Accepted }
\end{array}
$$

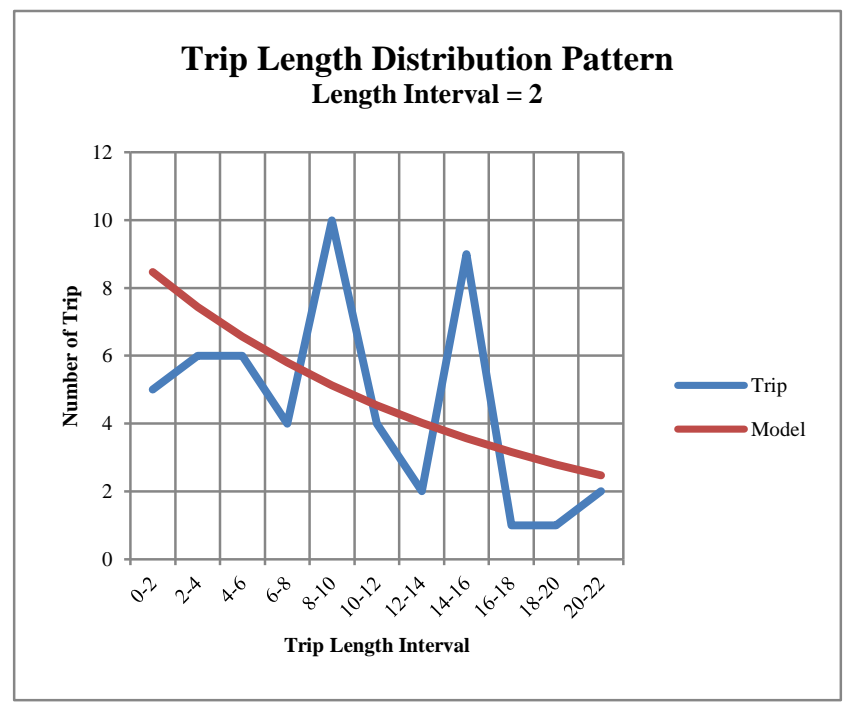

Figure 2. TLD Pattern for Trip Length Interval = 2

\begin{tabular}{|c|c|c|c|c|c|c|c|c|}
\hline \multicolumn{2}{|c|}{ Data } & \multicolumn{5}{|c|}{ Model Development } & \multicolumn{2}{|c|}{ Check } \\
\hline \multirow{2}{*}{ Range } & \multirow{2}{*}{ Trip } & C & $\alpha$ & $\beta$ & \multirow{2}{*}{ Model } & \multirow{2}{*}{$\mathbf{e}_{i}^{2}$} & Curve & Error \\
\hline & & 9.0 & 0.01 & 0.06 & & & $<16.92$ & $<10 \%$ \\
\hline $0-2$ & 5 & 9.0 & 1.000 & 0.942 & 8.476 & 12.082 & 2.42 & 69.52 \\
\hline $2-4$ & 6 & 9.0 & 0.989 & 0.835 & 7.435 & 2.060 & 0.34 & 23.92 \\
\hline $4-6$ & 6 & 9.0 & 0.984 & 0.741 & 6.561 & 0.315 & 0.05 & 9.35 \\
\hline 6-8 & 4 & 9.0 & 0.981 & 0.657 & 5.799 & 3.238 & 0.81 & 44.99 \\
\hline $8-10$ & 10 & 9.0 & 0.978 & 0.583 & 5.131 & 23.710 & 2.37 & 48.69 \\
\hline $10-12$ & 4 & 9.0 & 0.976 & 0.517 & 4.541 & 0.293 & 0.07 & 13.54 \\
\hline $12-14$ & 2 & 9.0 & 0.975 & 0.458 & 4.021 & 4.085 & 2.04 & 101.06 \\
\hline $14-16$ & 9 & 9.0 & 0.973 & 0.407 & 3.561 & 29.579 & 3.29 & 60.43 \\
\hline $16-18$ & 1 & 9.0 & 0.972 & 0.361 & 3.155 & 4.643 & 4.64 & 215.47 \\
\hline $18-20$ & 1 & 9.0 & 0.971 & 0.320 & 2.795 & 3.222 & 3.22 & 179.49 \\
\hline \multirow[t]{3}{*}{$20-22$} & 2 & 9.0 & 0.970 & 0.284 & 2.476 & 0.227 & 0.11 & 23.82 \\
\hline & & & & & & 83.452 & 19.37 & 71.84 \\
\hline & & & & & \multicolumn{2}{|l|}{ Acce } & NA & NA \\
\hline
\end{tabular}

TABLE 2.

MODEL DEVELOPMENT FOR TRIP LENGTH INTERVAL $=2$

Trip Length Interval $3 \mathrm{~km}$

Calculation result for Trip Length Interval $=3$ indicate that the TLD Pattern is irregular. No special pattern occurs. The Tanner Model has been developed and the result indicates that the Curve Fitting is NA, the Error is NA. The Trip Length Interval $=3$ is not appropriate to be used for developing Deterrence Function.

The Deterrence Function, the graph of TLP Pattern with Deterrence Function and also the Calculation is presented in Equation 13, Figure 3 and Table 3 below.

$$
\begin{aligned}
& \mathrm{f}(\mathrm{L})=11.5 \times \mathrm{L} \mathrm{L}^{-0.01} \times \mathrm{xe}^{-0.04 \mathrm{~L}} \\
& \chi^{2}=30.51>11.07 \quad \rightarrow \text { Not Accepted } \\
& \text { Error }=101.02 \%>10 \% \quad \rightarrow \text { Not Accepted }
\end{aligned}
$$

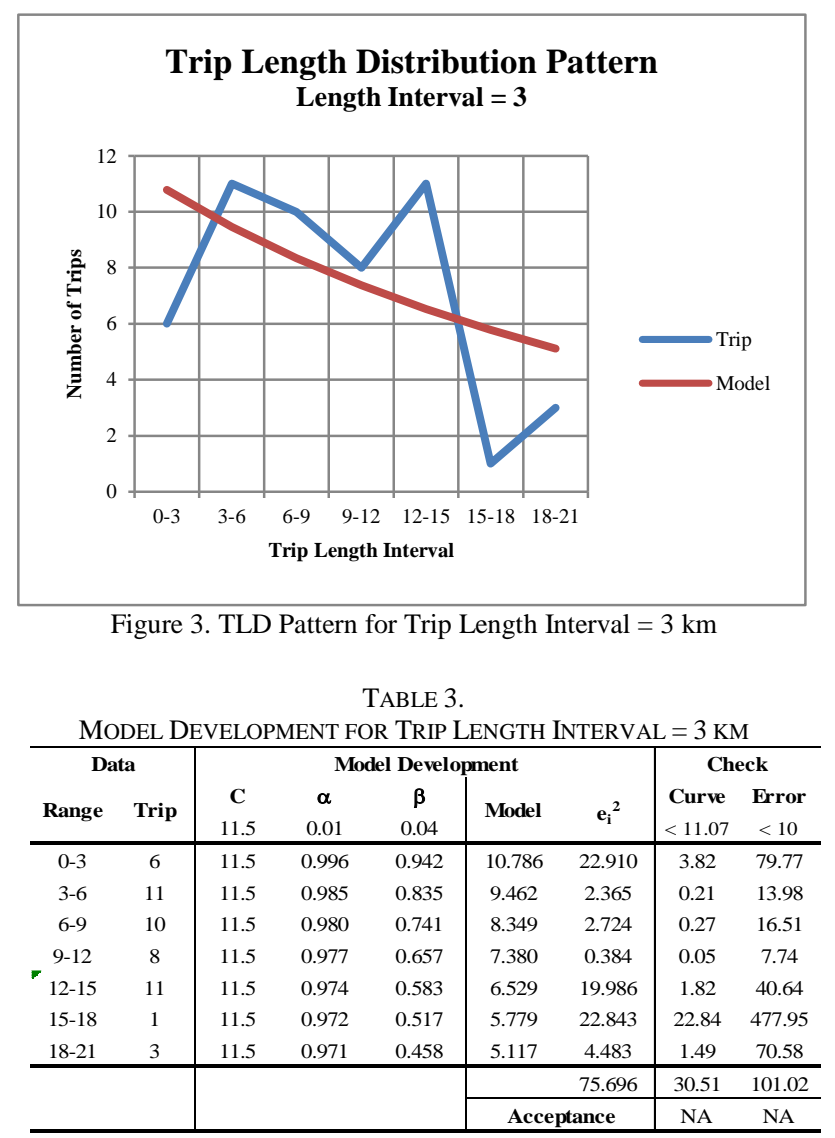


Trip Length Interval $4 \mathrm{~km}$

Calculation result for Trip Length Interval $=4$ indicate that the TLD Pattern is started to be regular. Special pattern started to occur. The Tanner Model has been developed and the result indicates that the Curve Fitting is NA, the Error is NA. The Trip Length Interval $=4$ is started to be appropriate to be used for developing Deterrence Function.

The Deterrence Function, the graph of TLP Pattern with Deterrence Function and also the Calculation is presented in Equation 14, Figure 4 and Table 4 below.

$$
\begin{aligned}
& \mathrm{f}(\mathrm{L})=15.5 \times \mathrm{L}^{-0.01} \mathrm{x} \mathrm{e}^{-0.05 \mathrm{~L}} \\
& \chi^{2}=16.72>9.49 \rightarrow \text { Not Accepted } \\
& \text { Error }=76.98 \%>10 \% \quad \rightarrow \text { Not Accepted }
\end{aligned}
$$

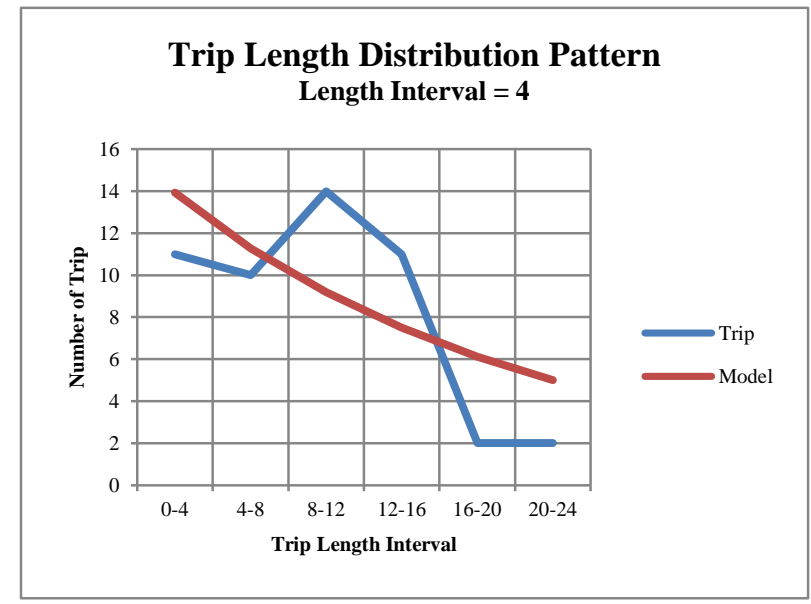

Figure 4. TLD Pattern for Trip Length Interval $=4$

\begin{tabular}{|c|c|c|c|c|c|c|c|c|}
\hline \multicolumn{2}{|c|}{ Data } & \multicolumn{5}{|c|}{ Model Development } & \multicolumn{2}{|c|}{ Check } \\
\hline \multirow{2}{*}{ Range } & \multirow{2}{*}{ Trip } & C & $\alpha$ & $\beta$ & \multirow{2}{*}{ Model } & \multirow{2}{*}{$\mathbf{e}_{i}^{2}$} & Curve & Error \\
\hline & & 15.5 & 0.01 & 0.05 & & & $<9.49$ & $<10$ \\
\hline $0-4$ & 11 & 15.5 & 0.993 & 0.905 & 13.928 & 8.574 & 0.78 & 26.62 \\
\hline $4-8$ & 10 & 15.5 & 0.982 & 0.741 & 11.279 & 1.635 & 0.16 & 12.79 \\
\hline 8-12 & 14 & 15.5 & 0.977 & 0.607 & 9.187 & 23.163 & 1.65 & 34.38 \\
\hline $12-16$ & 11 & 15.5 & 0.974 & 0.497 & 7.497 & 12.274 & 1.12 & 31.85 \\
\hline $16-20$ & 2 & 15.5 & 0.972 & 0.407 & 6.122 & 16.993 & 8.50 & 206.11 \\
\hline \multirow[t]{3}{*}{ 20-24 } & 2 & 15.5 & 0.970 & 0.333 & 5.002 & 9.015 & 4.51 & 150.12 \\
\hline & & & & & & 71.654 & 16.72 & 76.98 \\
\hline & & & & & Acce & ance & NA & NA \\
\hline
\end{tabular}

TABLE 4.

MODEL DEVELOPMENT FOR TRIP LENGTH INTERVAL $=4$

Trip Length Interval $5 \mathrm{~km}$

Calculation result for Trip Length Interval $=5$ indicate that the TLD Pattern has a special pattern. The Tanner Model has been developed and the result indicates that the Curve Fitting is NA, the Error is NA. The Trip Length Interval $=5$ is appropriate to be used for developing Deterrence Function.

The Deterrence Function, the graph of TLP Pattern with Deterrence Function and also the Calculation is presented in Equation 15, Figure 5 and Table 5 below.

$$
\begin{aligned}
& f(L)=20.2 \times L^{-0.01} \times \mathrm{e}^{-0.06 L} \\
& \chi^{2}=21.73>7.81 \quad \rightarrow \text { Not Accepted } \\
& \text { Error }=99.53 \%>10 \% \quad \rightarrow \text { Not Accepted }
\end{aligned}
$$

\begin{tabular}{|c|c|c|c|c|c|c|c|c|}
\hline \multicolumn{2}{|c|}{ Data } & \multicolumn{5}{|c|}{ Model Development } & \multicolumn{2}{|c|}{ Check } \\
\hline \multirow{2}{*}{ Range } & \multirow{2}{*}{ Trip } & C & $\alpha$ & $\beta$ & \multirow{2}{*}{ Model } & \multirow{2}{*}{$\mathbf{e}_{\mathbf{i}}{ }^{2}$} & Curve & Error \\
\hline & & 20.2 & 0.01 & 0.06 & & & $<7.81$ & $<10$ \\
\hline $0-5$ & 13 & 20.2 & 0.991 & 0.861 & 17.228 & 17.874 & 1.37 & 32.52 \\
\hline $5-10$ & 18 & 20.2 & 0.980 & 0.638 & 12.623 & 28.910 & 1.61 & 29.87 \\
\hline $10-15$ & 15 & 20.2 & 0.975 & 0.472 & 9.304 & 32.446 & 2.16 & 37.97 \\
\hline $15-20$ & 2 & 20.2 & 0.972 & 0.350 & 6.869 & 23.710 & 11.85 & 243.46 \\
\hline \multirow[t]{3}{*}{$20-25$} & 2 & 20.2 & 0.969 & 0.259 & 5.076 & 9.463 & 4.73 & 153.81 \\
\hline & & & & & & 112.403 & 21.73 & 99.53 \\
\hline & & & & & \multicolumn{2}{|c|}{ Acceptance } & NA & NA \\
\hline
\end{tabular}

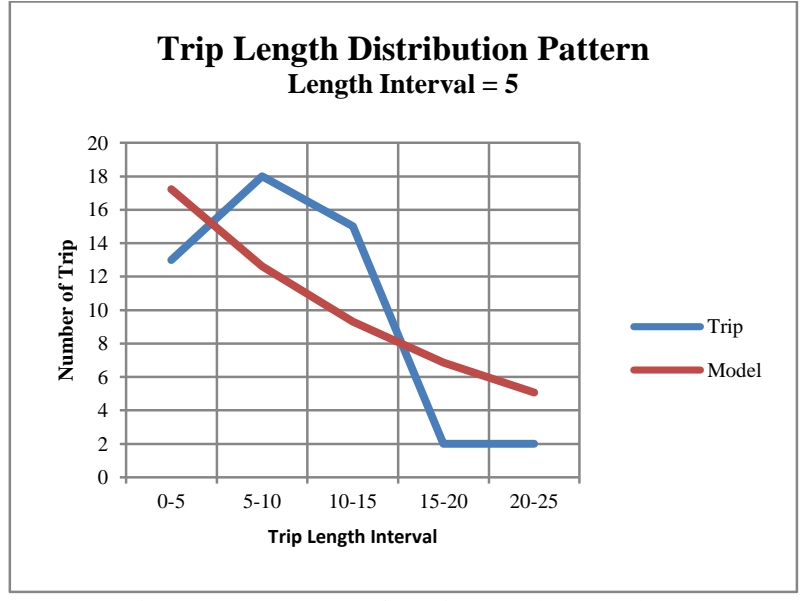

Figure 5. TLD Pattern for Trip Length Interval = 5

TABLE 5.

MODEL DEVELOPMENT FOR TRIP LENGTH INTERVAL $=5$

Trip Length Interval $6 \mathrm{~km}$

Calculation result for Trip Length Interval $=6$ indicate that the TLD Pattern has a special pattern. The Tanner Model has been developed and the result indicates that the Curve Fitting is NA, the Error is NA. The Trip Length Interval $=6$ is appropriate to be used for developing Deterrence Function.

The Deterrence Function, the graph of TLP Pattern with Deterrence Function and also the Calculation is presented in Equation 16, Figure 6 and Table 6 below.

$$
\begin{aligned}
& f(L)=24.1 \times L^{-0.01} \times e^{-0.06 L} \\
& \chi^{2}=6.41>5.99 \rightarrow \text { Not Accepted } \\
& \text { Error }=45.59 \%>10 \% \quad \rightarrow \text { Not Accepted }
\end{aligned}
$$

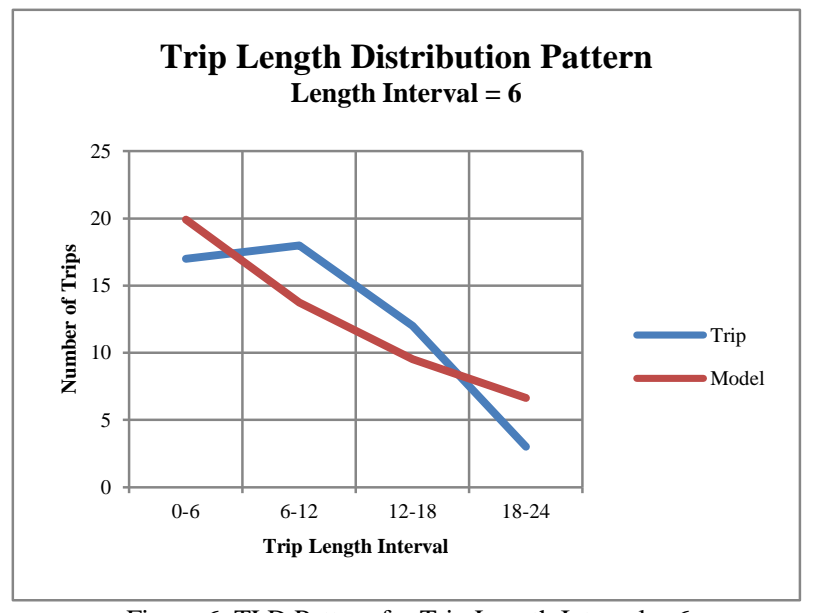

Figure 6. TLD Pattern for Trip Length Interval $=6$ 
TABLE 6.

MODEL DEVELOPMENT FOR TRIP LENGTH INTERVAL $=6$

\begin{tabular}{|c|c|c|c|c|c|c|c|c|}
\hline \multicolumn{2}{|c|}{ Data } & \multicolumn{5}{|c|}{ Model Development } & \multicolumn{2}{|c|}{ Check } \\
\hline \multirow{2}{*}{ Range } & \multirow{2}{*}{ Trip } & C & $\alpha$ & $\beta$ & \multirow{2}{*}{ Model } & \multirow{2}{*}{$\mathbf{e}_{i}{ }^{2}$} & Curve & Error \\
\hline & & 24.1 & 0.01 & 0.06 & & & $<5.99$ & $<10$ \\
\hline $0-6$ & 17 & 24.1 & 0.989 & 0.835 & 19.910 & 8.469 & 0.50 & 17.12 \\
\hline $6-12$ & 18 & 24.1 & 0.978 & 0.583 & 13.739 & 18.156 & 1.01 & 23.67 \\
\hline $12-18$ & 12 & 24.1 & 0.973 & 0.407 & 9.537 & 6.069 & 0.51 & 20.53 \\
\hline \multirow[t]{3}{*}{$18-24$} & 3 & 24.1 & 0.970 & 0.284 & 6.631 & 13.185 & 4.39 & 121.04 \\
\hline & & & & & & 45.878 & 6.41 & 45.59 \\
\hline & & & & & Acc & ance & NA & NA \\
\hline
\end{tabular}

Trip Length Interval 7 km

Calculation result for Trip Length Interval $=7$ indicate that the TLD Pattern has a special pattern occur. The Tanner Model has been developed and the result indicates that the Curve Fitting is NA, the Error is NA. The Trip Length Interval $=7$ is appropriate to be used for developing Deterrence Function.

The Deterrence Function, the graph of TLP Pattern with Deterrence Function and also the Calculation is presented in Equation 17, Figure 7 and Table 7 below.

$$
\begin{aligned}
& \mathrm{f}(\mathrm{L})=26.5 \times \mathrm{L}^{-0.01} \times \mathrm{x}^{-0.04 \mathrm{~L}} \\
& \chi^{2}=0.80>3.84 \quad \rightarrow \text { Accepted } \\
& \text { Error }=8.96 \%>10 \% \quad \rightarrow \text { Accepted }
\end{aligned}
$$

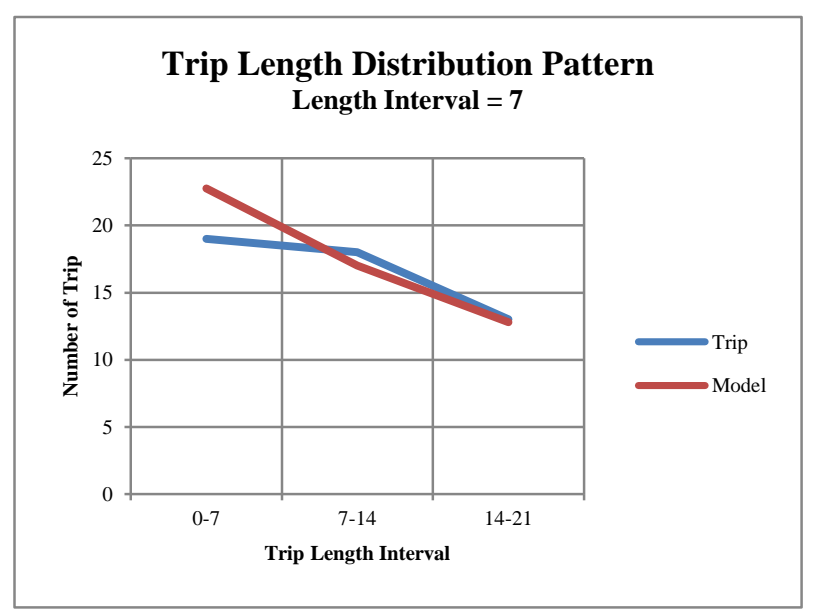

Figure 7. TLD Pattern for Trip Length Interval $=7$

\begin{tabular}{|c|c|c|c|c|c|c|c|c|}
\hline \multicolumn{2}{|c|}{ Data } & \multicolumn{5}{|c|}{ Model Development } & \multicolumn{2}{|c|}{ Check } \\
\hline \multirow{2}{*}{ Range } & \multirow{2}{*}{ Trip } & $\mathrm{C}$ & $\alpha$ & $\beta$ & \multirow{2}{*}{ Model } & \multirow{2}{*}{$\mathbf{e}_{i}{ }^{2}$} & Curve & Error \\
\hline & & 26.5 & 0.01 & 0.04 & & & $<3.84$ & $<10$ \\
\hline $0-7$ & 19 & 26.5 & 0.988 & 0.869 & 22.751 & 14.071 & 0.74 & 19.74 \\
\hline $7-14$ & 18 & 26.5 & 0.977 & 0.657 & 17.007 & 0.986 & 0.05 & 5.52 \\
\hline \multirow[t]{3}{*}{$14-21$} & 13 & 26.5 & 0.972 & 0.497 & 12.788 & 0.045 & 0.00 & 1.63 \\
\hline & & & & & & 15.102 & 0.80 & 8.96 \\
\hline & & & & & \multicolumn{2}{|c|}{ Acceptance } & OK & OK \\
\hline
\end{tabular}

TABLE 7.

MODEL DEVELOPMENT FOR TRIP LENGTH INTERVAL $=7$

Trip Length Interval $8 \mathrm{~km}$

Calculation result for Trip Length Interval $=8$ indicate that the TLD Pattern has a special pattern occurs. The Tanner Model has been developed and the result indicates that the Curve Fitting is NA, the Error is NA. The Trip Length Interval $=8$ is appropriate to be used for developing Deterrence Function.

The Deterrence Function, the graph of TLP Pattern with Deterrence Function and also the Calculation is presented in Equation 18, Figure 8 and Table 8 below.

$$
\begin{aligned}
& \mathrm{f}(\mathrm{L})=29.8 \times \mathrm{L}^{-0.01} \times \mathrm{e}^{-0.05 \mathrm{~L}} \\
& \chi^{2}=14.74>3.84 \quad \rightarrow \text { Not Accepted } \\
& \text { Error }=72.25 \%>10 \% \quad \rightarrow \text { Not Accepted }
\end{aligned}
$$

\begin{tabular}{|c|c|c|c|c|c|c|c|}
\hline Data & \multicolumn{5}{|c|}{ Model Development } & \multicolumn{2}{|c|}{ Check } \\
\hline nge & C & $\alpha$ & $\beta$ & \multirow{2}{*}{ Model } & \multirow{2}{*}{$\mathbf{e}_{i}{ }^{2}$} & Curve & Error \\
\hline IIP & 29.8 & 0.01 & 0.05 & & & $<3.84$ & $<10$ \\
\hline $0-8$ & 29.8 & 0.986 & 0.819 & 24.062 & $\begin{array}{l}9.378 \\
\end{array}$ & 0.45 & 14.58 \\
\hline 3-16 & 29.8 & 0.975 & 0.549 & 15.953 & 81.845 & 3.27 & 36.19 \\
\hline \multirow[t]{3}{*}{$16-24$} & 29.8 & 0.970 & 0.368 & 10.639 & 44.080 & 11.02 & 165.98 \\
\hline & & & & & 135.302 & 14.74 & 72.25 \\
\hline & & & & Acc & tance & NA & NA \\
\hline
\end{tabular}

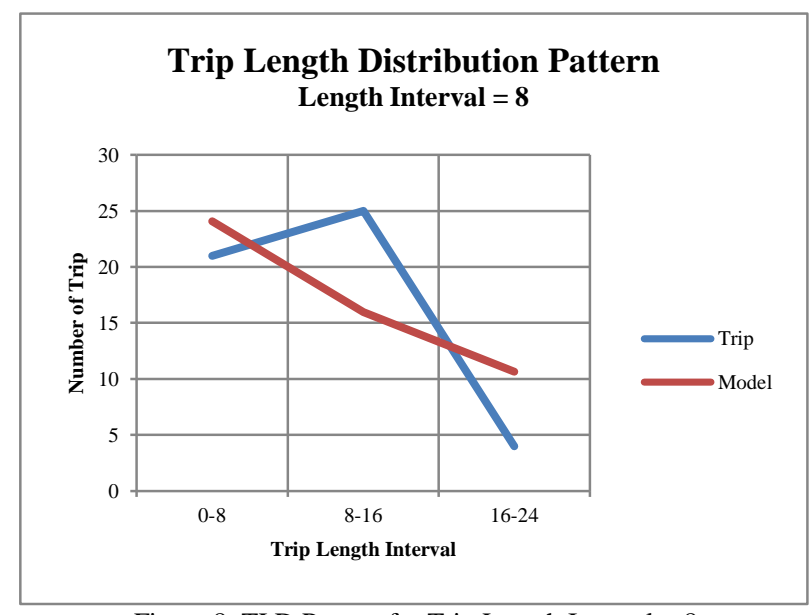

Figure 8. TLD Pattern for Trip Length Interval $=8$

TABLE 8.

D. Summary

The investigation shows us that the Trip Length Distribution Patterns are very irregular in low value Trip Length Interval and it become more regular and inconcordance with the general rule of TLD Pattern as the Trip Length Interval getting higher and higher. For TLI of 1 $-2 \mathrm{~km}$, the two patterns are very irregular. For the TLI of 3 $-4 \mathrm{~km}$, the patterns start to be regular. All the patterns for TLI of $5-8 \mathrm{~km}$ are good. The TLD Pattern comparison is presented in Figure 9 below.

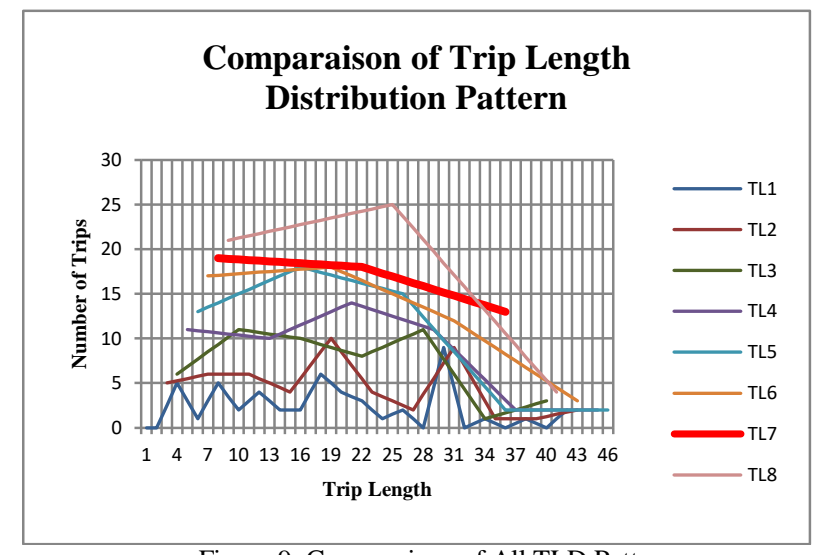

Figure 9. Comparaison of All TLD Pattern

All Deterrence Function have the same pattern with different slope value. The higher the TLI value, the steeper the slopes are. The Deterrence Function of TLI $7 \mathrm{~km}$ is the only one accepted. The comparison of Deterrence Functions is presented in Figure 10 and Table 9 below. 


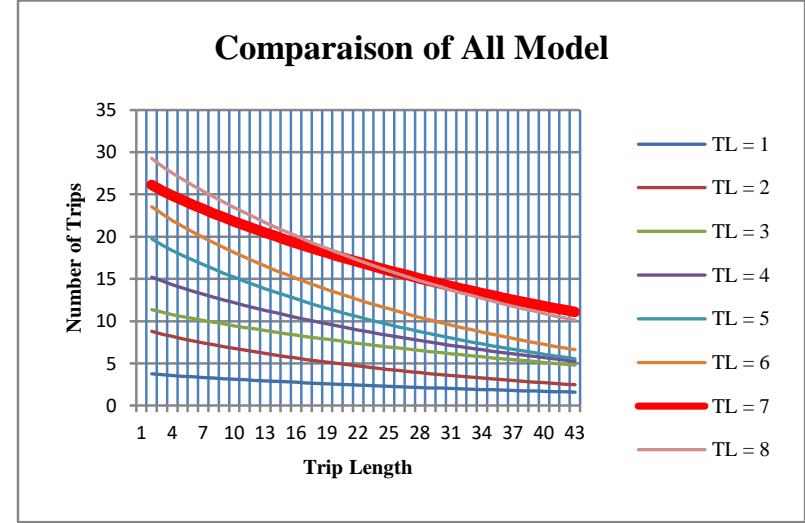

Figure 10. Comparaison of All Deterrence Functions

TABLE 9.

COMPARISON OF DETERRENCE FUNCTION FOR ALL TRIP LENGTH

\begin{tabular}{|c|c|c|c|c|c|c|c|c|}
\hline \multicolumn{9}{|c|}{ INTERVALS } \\
\hline \multirow{3}{*}{ Range } & \multicolumn{3}{|c|}{ Model Parameter } & \multicolumn{5}{|c|}{ Quality Check } \\
\hline & \multirow{2}{*}{ C } & \multirow{2}{*}{$\alpha$} & \multirow[b]{2}{*}{$\beta$} & \multicolumn{3}{|c|}{ Curve Fitting } & \multicolumn{2}{|c|}{ Error } \\
\hline & & & & $\chi_{0, \mathrm{i}}^{2}$ & $\chi_{i}^{2}$ & Accept. & $\%$ & Accept \\
\hline 1 & 3.8 & 0.01 & 0.04 & $<30.14$ & \#DIV/0! & NA & \#DIV/0! & NA \\
\hline 2 & 9.0 & 0.01 & 0.06 & $<16.92$ & 19.37 & NA & 71.84 & NA \\
\hline 3 & 11.5 & 0.01 & 0.04 & $<11.07$ & 30.51 & NA & 101.02 & NA \\
\hline 4 & 15.5 & 0.01 & 0.05 & $<9.49$ & 16.72 & NA & 76.98 & NA \\
\hline 5 & 20.2 & 0.01 & 0.06 & $<7.81$ & 21.73 & NA & 99.53 & NA \\
\hline 6 & 24.1 & 0.01 & 0.06 & $<5.99$ & 6.41 & NA & 45.59 & NA \\
\hline 7 & 26.5 & 0.01 & 0.04 & $<3.84$ & 0.80 & OK & 8.96 & OK \\
\hline 8 & 29.8 & 0.01 & 0.05 & $<3.84$ & 14.74 & NA & 72.25 & NA \\
\hline
\end{tabular}

\section{CONCLUSION}

Research questions have been answered satisfactorily. Principal conclusions can be drawn as follows:

- Different trip length interval, for the same trip length data, gives different trip length distribution pattern and the difference can be very significant. Different Pattern produces different Deterrence Function.

- Trip Length Intervals of $1-2 \mathrm{~km}$ give irregular pattern. Trip Length Interval of 3-4 km started to give regular pattern. While Trip Length Interval of $5-8 \mathrm{~km}$ give very regular pattern.

- Trip Length Interval of 1-2 km cannot be used for developing Deterrence Function.

- Modeled by using Tanner Deterrence Function, the Trip Length Interval of $7 \mathrm{~km}$ gives an accepted result.

- A Deterrence Function with a Good $\chi^{2}$ value does not always have accepted error.
The research must be continued to investigate the TLD Pattern based on more sample and more trip purpose category, to investigate the deterrence function behavior and to investigate deterrence function development method. A reflexion related to the real Transport Model must be thought.

Notes. This research is part of the main research to develop a Special Conventional Transport Model for predicting passenger demand for a New Mass Transit Line.

\section{REFERENCES}

[1] O. Z. Tamin, Perencanaan,Pemodelan,\&amp; Rekayasa Transportasi:Teori, Contoh Soal, dan Aplikasi. Bandung: ITB, 2008.

[2] H. Suprayitno, "Metoda Penilaian Kualitas Jaringan Jalan Utama di Wilayah Kabupaten,” Institut Teknologi Sepuluh Nopember, 2014.

[3] H. Suprayitno and V. Ananda Upa, "Mamminasata BRT User Trip Characteristics for the Design of Demand Modelling Method for a New BRT Line,” IPTEK J. Technol. Sci., vol. 27, no. 3, pp. 47-52, Jan. 2017.

[4] H. Suprayitno and V. A. Upa, "Special Conventional Transport Model for a New BRT Line Passenger Demand Prediction The General Modeling Method," in Proceedings of International Conference on Technology and Social Science, 2017.

[5] H. Suprayitno, N. Saraswati, and C. P. Fajrinia, "Developing a method for measuring the quality of a sample based trip length distribution for urban trip," Rekayasa Tek. Sipil, vol. 3, no. 3, pp. 252-258, 2016.

[6] H. Suprayitno, V. Ratnasari, and N. Saraswati, "Experiment Design for Determining the Minimum Sample Size for Developing Sample Based Trip Length Distribution," in IOP Conference Series: Materials Science and Engineering, 2017, vol. 267, no. 1, p. 012029.

[7] AECOM, "FY 2015 South Jersey travel demand model recalibration and improvements," 2015.

[8] N. J. Jonker, "Modelling the trip length distribution of shopping trips from GPS data," University of Pretoria, 2016.

[9] D. F. Pearson, V. G. Stover, and J. D. Benson, "A procedure for estimation of trip length frequency distributions,” Texas, 1974.

[10] N. D. A. Praditya, "Pemodelan transportasi moda sepeda motor kota Samarinda untuk tahun 2016," Institut Teknologi Sepuluh Nopember, 2017.

[11] L. T. Blank, Statistical procedures for engineering, management, and science / Leland Blank. - Version details - Trove. New York: McGraw-Hill, 1982.

[12] A. M. Brown, "A step-by-step guide to non-linear regression analysis of experimental data using a Microsoft Excel spreadsheet," Comput. Methods Programs Biomed., vol. 65, no. 3, pp. 191-200, Jun. 2001.

[13] H. Suprayitno and V. Ratnasari, "Reflexion on linear regression trip production modelling method for ensuring good model quality," in AIP Conference Proceedings, 2017, vol. 1903, no. 1, p. 060013. 